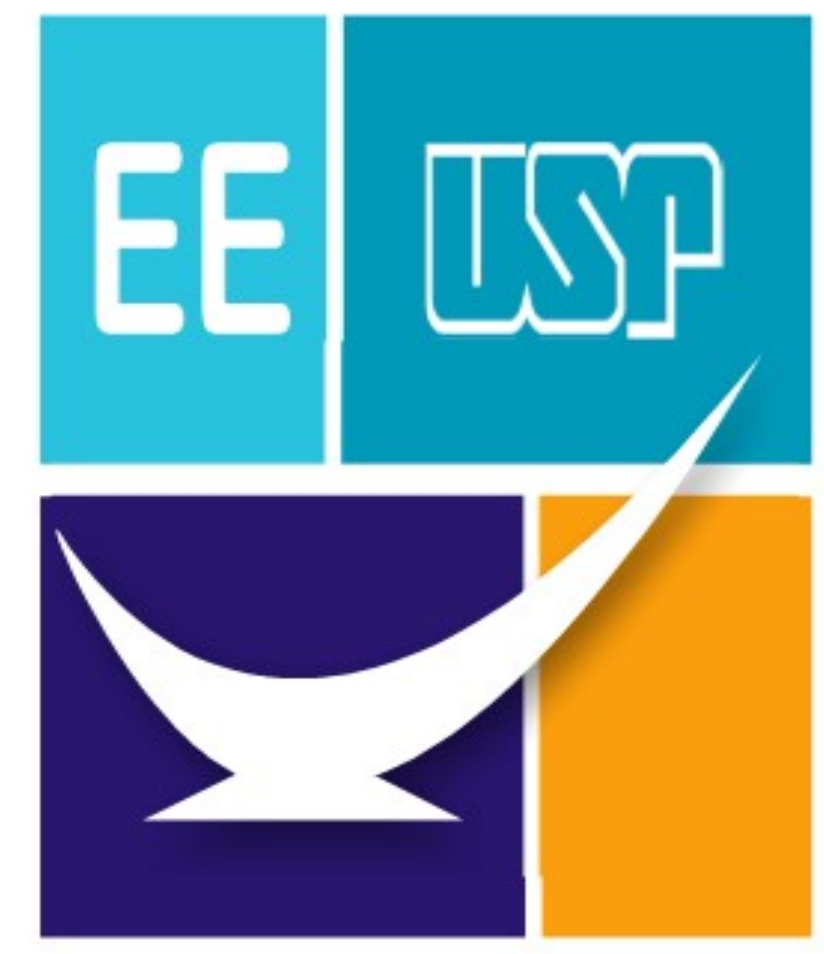

ENFERMAGEM

\title{
PROGRAMA NACIONAL DE SEGURANÇA DO PACIENTE NO BRASIL: REVISÃO DE DOCUMENTOS OFICIAIS
}

\section{Andressa Garcia Nicole ${ }^{1,2}$, Alexandre Souza Morais ${ }^{1,2}$, Marta Maria Melleiro ${ }^{1}$, Daisy M. Rizatto Tronchin ${ }^{1}$}

1 Universidade de São Paulo, Escola de Enfermagem. São Paulo, SP, Brasil

2 Universidade Federal do Espírito Santo. Departamento de Ciências da Saúde. São Mateus, ES, Brasil.

\section{INTRODUÇÃO}

O Programa Nacional de Segurança do Paciente (PNSP) foi instituído no Brasil em 2013, configurando-se como a primeira política pública específica para essa área temática. ${ }^{(1)} \mathrm{O}$ direcionamento das ações para efetivação do PNSP é competência da Agência Nacional de Vigilância Sanitária (ANVISA), sendo subdividido em quatro eixos temáticos:

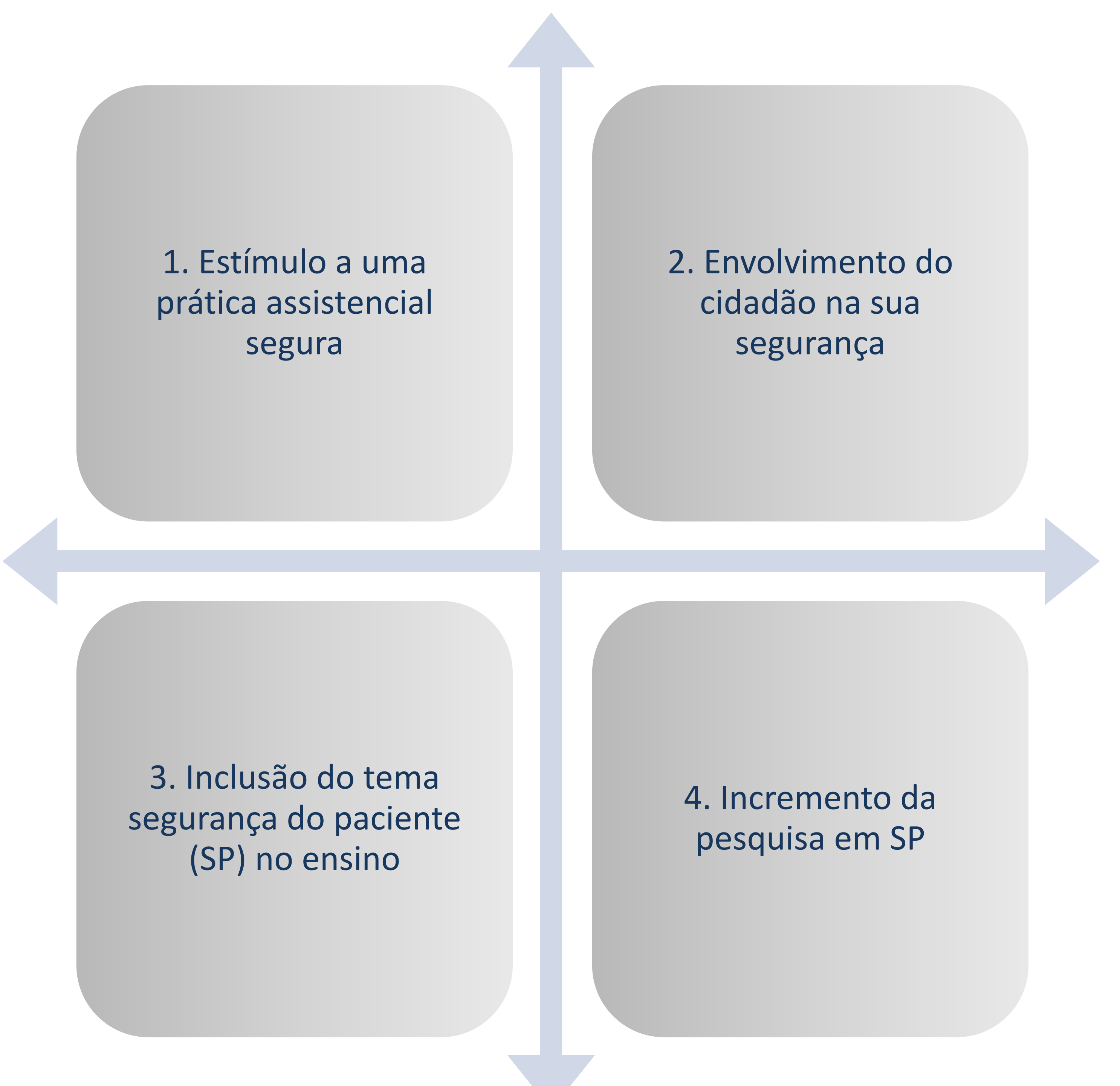

\section{OBJETIVO}

$>$ Analisar os documentos oficiais publicados pela ANVISA relacionadas ao PNSP contemplados nos eixos 1 e 2.

\section{MÉTODO}

Estudo documental, baseado em arquivos disponíveis para consulta por meio eletrônico no portal da ANVISA, referente ao PNSP, publicados entre abril de 2013 e agosto de 2018. O acesso aos documentos ocorreu no mês de setembro de 2018.

\section{RESULTADOS}

Foram analisados 54 documentos oficiais.

Gráfico 1 - Distribuição dos documentos oficiais da ANVISA relativos ao PNSP, segundo o ano de publicação, Brasil - 2019.

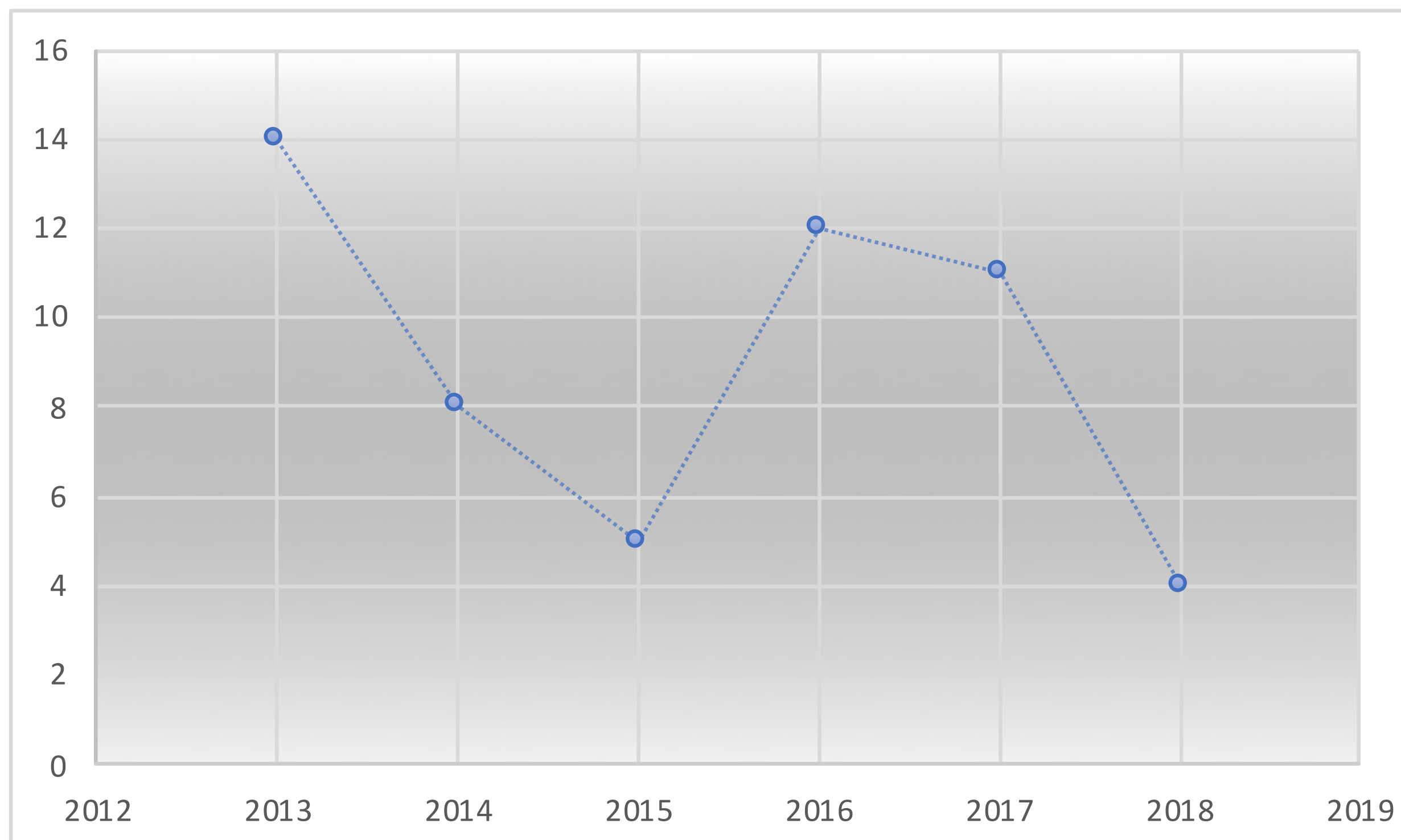

Gráfico 2 - Distribuição dos documentos oficiais da ANVISA relativos ao PNSP, segundo o tipo de publicação, Brasil - 2019.

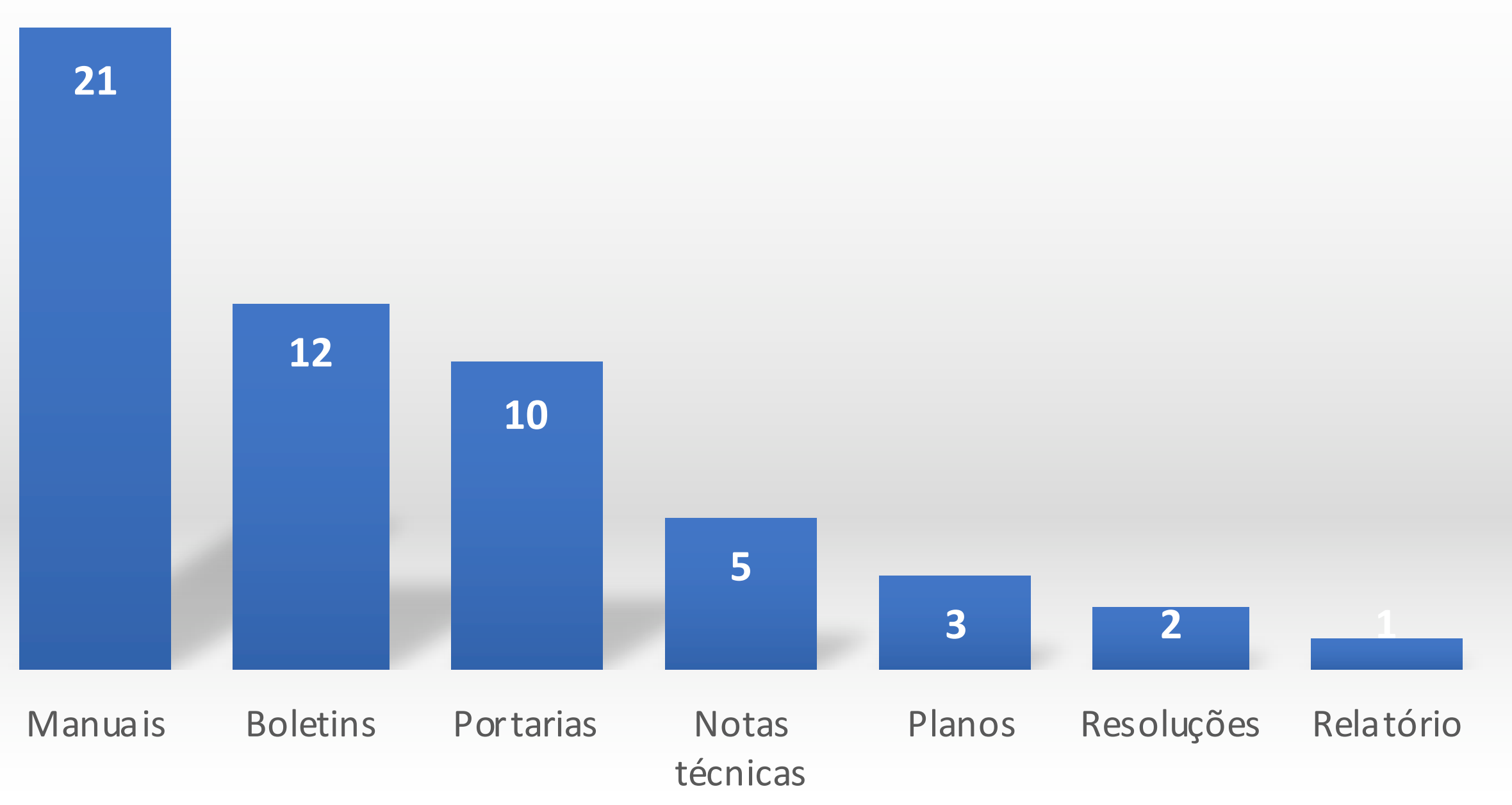

Gráfico 3 - Distribuição dos documentos oficiais da ANVISA relativos ao PNSP, segundo a área temática, Brasil - 2019.

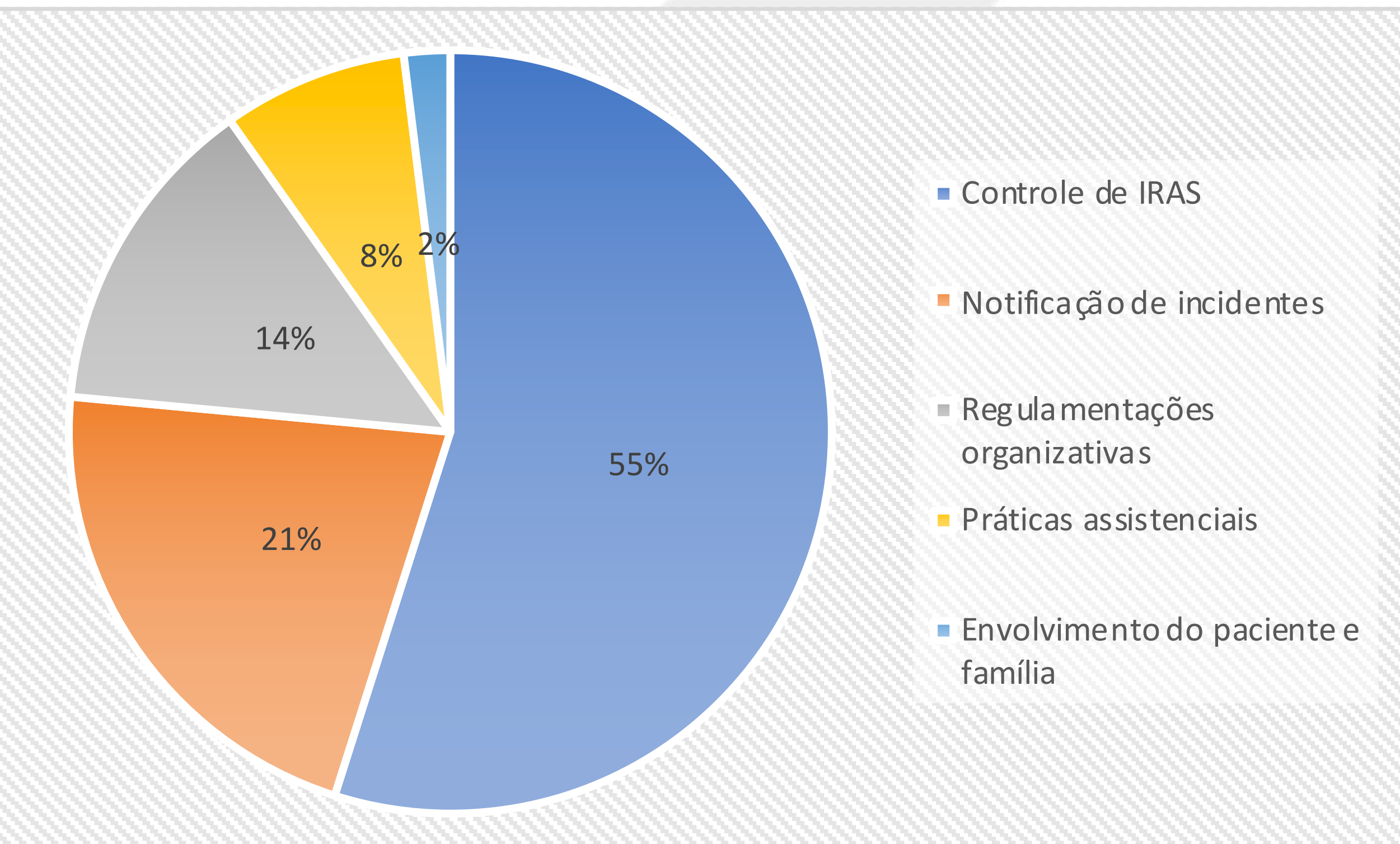

\section{CONCLUSÃO}

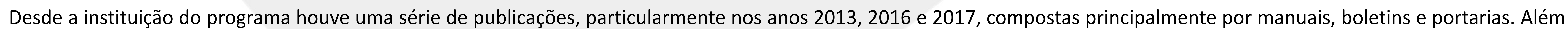

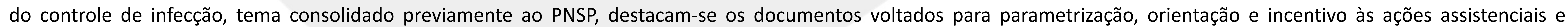

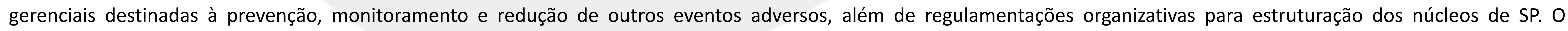
envolvimento do paciente, porém, tem sido um tema pouco explorado, indicando necessidade de incrementar ações que fortaleçam o eixo 2 do PNSP.

\section{REFERÊNCIA}

1. Brasil. Ministério da Saúde. Fundação Oswaldo Cruz. Agência Nacional de Vigilância Sanitária. Documento de referência para o Programa Nacional de Segurança do Paciente. Brasília: Ministério da Saúde, 2014

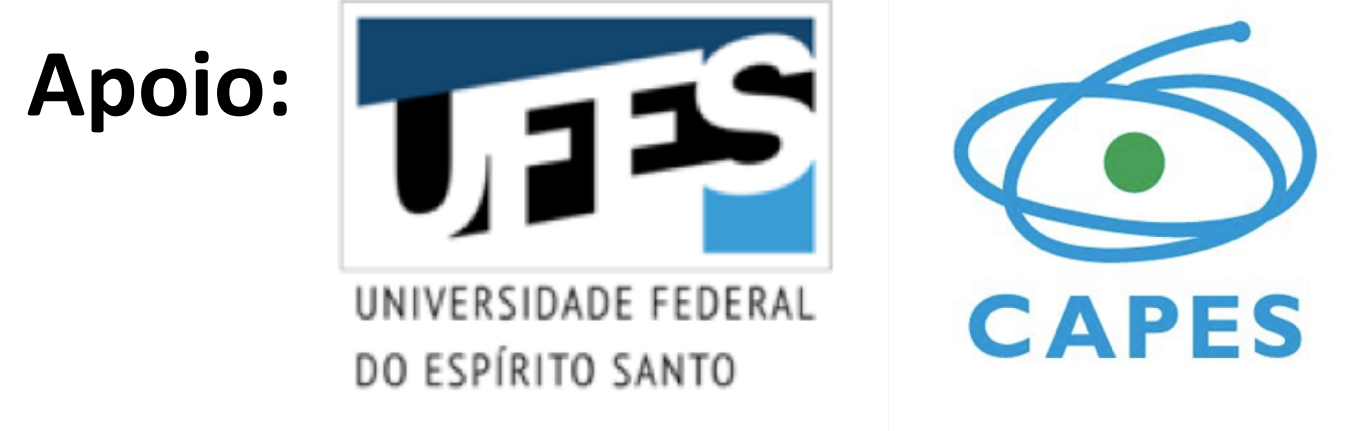

